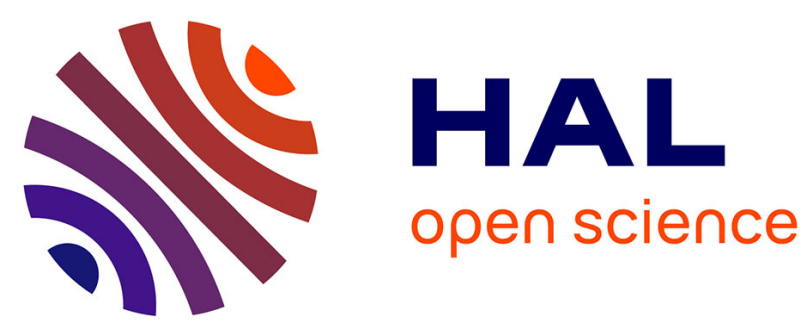

\title{
Flow cytometry and cytomorphology evaluation of hematologic malignancy in cerebrospinal fluids: comparison with retrospective clinical outcome
}

Clara Cesana, Catherine Klersy, Barbara Scarpati, Bruno Brando, Maurizio Faleri, Giambattista Bertani, Arianna Gatti, Elisabetta Volpato, Claudia Barba, Ursula Ferri, et al.

\section{To cite this version:}

Clara Cesana, Catherine Klersy, Barbara Scarpati, Bruno Brando, Maurizio Faleri, et al.. Flow cytometry and cytomorphology evaluation of hematologic malignancy in cerebrospinal fluids: comparison with retrospective clinical outcome. Annals of Hematology, 2011, 90 (7), pp.827-835. 10.1007/s00277010-1145-4 . hal-00615418

\section{HAL Id: hal-00615418 https://hal.science/hal-00615418}

Submitted on 19 Aug 2011

HAL is a multi-disciplinary open access archive for the deposit and dissemination of scientific research documents, whether they are published or not. The documents may come from teaching and research institutions in France or abroad, or from public or private research centers.
L'archive ouverte pluridisciplinaire HAL, est destinée au dépôt et à la diffusion de documents scientifiques de niveau recherche, publiés ou non, émanant des établissements d'enseignement et de recherche français ou étrangers, des laboratoires publics ou privés. 


\section{FLOW CYTOMETRY AND CYTOMORPHOLOGY EVALUATION OF HEMATOLOGIC MALIGNANCY IN CEREBROSPINAL FLUIDS: COMPARISON WITH RETROSPECTIVE CLINICAL OUTCOME}

Clara Cesana ${ }^{1}$, Catherine Klersy ${ }^{2}$, Barbara Scarpati ${ }^{1}$, Bruno Brando ${ }^{3}$, Maurizio Faleri ${ }^{4}$, Giambattista Bertani ${ }^{1}$, Arianna Gatti ${ }^{3}$, Elisabetta Volpato ${ }^{1}$, Claudia Barba ${ }^{1}$, Ursula Ferri ${ }^{1}$, Linda Scampini ${ }^{1}$, Giovanni Grillo ${ }^{1}$, Giuliana Lando ${ }^{1}$, Annamaria Nosari ${ }^{1}$, Enrica Morra ${ }^{1}$, and Roberto Cairoli ${ }^{1}$

${ }^{1}$ Department of Transfusion Medicine and Division of Hematology; ${ }^{4}$ Division of Surgical Pathology and Cytogenetics; Ospedale Niguarda Ca' Granda Hospital, Milan, Italy;

${ }^{2}$ Service of Biometry and Clinical Epidemiology, Fondazione IRCCS Policlinico San Matteo, Pavia, Italy; ${ }^{3}$ Blood Center and Hematology Laboratory, Legnano Hospital, Legnano, Italy

Running Title: Hematologic Neoplasm Detection in Cerebrospinal Fluid

\section{Corresponding Author:}

Clara Cesana, MD

Department of Transfusion Medicine and Division of Hematology,

Ospedale Niguarda Ca' Granda Hospital

Piazza Ospedale Maggiore, 3, 20162 Milano, Italy

Tel: $\quad 390264443198$

Fax: $\quad 39026430755$

Email: clara.cesana@ospedaleniguarda.it 


\section{Abstract}

An independent clinical assessment was compared with flow cytometry (FCM) and cytomorphology results obtained on 227 cerebrospinal fluids investigated for hematologic malignancy, in a retrospective longitudinal study with a median observation time of 11 months. A combined method assessment (CMA), defining 'positive' a sample if at least one method gave 'positive' results, was also tested. Eleven out of 55 screening samples and 53 out of 166 follow-up samples resulted positive at clinical evaluation. FCM and CM were concordant with positive clinical assessment in $68.5 \%$ and $51.5 \%$ of cases, respectively. According to CMA, $10.5 \%$ of samples (resulting false negative by either FCM or cytomorphology) were rescued as true positive. FCM retained significantly higher accuracy than cytomorphology $(p=.0065)$ and $100 \%$ sensitivity when at least 220 leukocytes were acquired. CMA accuracy was higher than FCM accuracy and significantly higher than cytomorphology accuracy in the analysis of all samples $(p<.0001)$, samples from mature B-/T-cell neoplasms $(p=.0021)$, and samples drawn after intrathecal treatment $(p=.0001)$. When acquiring $\leq 220$ leukocytes, FCM accuracy was poor and combining cytomorphology added statistically significant diagnostic advantage $(p=.0043)$. Although FCM is the best diagnostic tool for evaluating CSF, morphology seems helpful especially when clinically positive follow-up samples are nearly acellular.

\section{Key-Words}

Cerebrospinal Fluid, Cytomorphology, Flow Cytometry, Hematologic Malignancy, Lymphoid Neoplasm 


\section{Introduction}

Cerebrospinal fluid (CSF) analysis by flow cytometry (FCM) and cytomorphology (CM) is currently requested to explore central nervous system (CNS) involvement by hematologic malignancy, both at diagnosis and during follow-up [1-11]. To date, the two methods have been mostly studied on CSF from newly diagnosed cases, i.e., those optimally evaluable samples not liable to intrathecal treatment-related damage [2-9]. In this setting, immunophenotype analysis is well known to guarantee the highest accuracy, morphologic exam still retaining an additional diagnostic value according to some authors [2,3,5$8,11,12]$. The point at issue related to CSF follow-up evaluations is possible lack of method accuracy due to poor cellularity and/or therapy-related cell changes $[11,13]$. Indeed, variable proportions of samples with the mentioned characteristics were arbitrarily excluded from the analysis as quantity not sufficient in previous reports [2-4,9-11]. Although CSF analysis is essential for the management of intra-thecal treatment schedules, the diagnostic performance of either FCM or CM in the follow-up setting is mostly unknown $[6,10,11]$. Moreover, whether the two methods retain differential accuracy in different diagnostic subgroups is largely undetermined [2-4,6-9].

In the present study, we matched immunophenotype and morphology results obtained from the analysis of 227 CSF, mostly drawn during follow-up, with an independent clinical outcome in a retrospective longitudinal study, in order to compare the accuracy of the two methods, and to explore a combined diagnostic approach assuring the best sensitivity in detecting hematologic malignancy, both in all conditions and in selected clinical settings.

\section{Materials And Methods}

Selection Criteria 
Among CSF analyzed by four-color FCM between 2002 and 2010, we selected those fulfilling each of the following criteria: (i) suspected/known hematologic malignancy at the time of withdrawal, (ii) CM performed on the same sample, and (iii) available follow-up findings for reliable retrospective clinical outcome. According to these criteria, 227 samples from 110 patients (69 males, 41 females) were included in a database and retrospectively examined (Table 1). The study was carried out according with the ethical standards of the Institutional Committee on Human Experimentation. Each patient gave informed consense to lumbar puncture (LP) in the context of his/her clinical management.

Sample Analysis

FCM and CM were carried out in two different laboratories, in a double blind manner. A sample volume of whatever size was accepted. Fresh specimens were processed within 3 hours from collection.

1. Immunophenotype

Samples were processed for four color analysis as previously described for effusions [14]. Monoclonal antibodies were dependent on patient's diagnosis and/or clinical history. All measurements were performed on a dual-laser FACSCalibur flow cytometer (Becton Dickinson, San José, CA, USA). Data were acquired with the CellQUEST software (Becton Dickinson), and analyzed with either CellQUEST or Paint-a-Gate softwares. Cell subpopulations, evaluated by means of multiparameter analysis including logical gates on forward scatter, side scatter, and FL1-FL4, were expressed both as number of acquired events and as percentages of $\mathrm{CD} 45^{+}$events.

2. Cytomorphology 
Samples were prepared by cytocentrifugation, using a Shandon cytospin4® (Thermo Shandon, Loughborough UK) at $250 \mathrm{rev} / \mathrm{min}$ for $15 \mathrm{~min}$, loading every funnel with $250 \mu \mathrm{l}$ of fluid. Slides were air-dried and stained with May Grünwald-Giemsa stain. When an opportunistic disease was clinically suspected, extra slides were alcohol-fixed for further appropriate stainings.

\section{Assessment Criteria}

Retrospective clinical outcome was expressed as positive or negative for neoplastic cells. It was formulated by the clinician regardless of the results obtained by FCM and $\mathrm{CM}$, and was based on clinical follow-up retrospectively collected for each case from the electronic hospital patient data management system. Retrospective clinical outcome positive for hematologic malignancy was defined as follows: (i) evidence of monoclonal cell population by molecular biology on the sample itself, or (ii) presence of CNS symptoms attributable to the disease at the time of LP and/or signs of CNS involvement at imaging data available within one moth after LP and/or malignant hematopoietic cells identified by CM and/or FCM in CSF samples drawn within one month after LP, with/without subsequent response to intrathecal treatment and/or to parenteral specific treatments. Retrospective clinical outcome negative for hematologic malignancy was defined as follows: (i) evidence of polyclonal cell population by molecular biology on the sample itself, or (ii) absence of CNS signs/symptoms as documented by clinical/imaging data, plus negative FCM/CM on CSF samples drawn in the aftermath, during a follow-up of at least 3 months after LP, or (iii) diagnosis of non-hematologic malignancy disease by means of laboratory and coltural tests plus no evidence of hematologic malignancy as documented by clinical and/or imaging data for at least three months after LP. 
FCM results were expressed as positive or negative for neoplastic cells (see below). CM results were expressed as positive (positive or uncertain results) or negative for neoplastic cells. A combined method assessment (CMA) was also established (positive if at least one method gave positive results, negative in the remaining cases). Samples with blood contamination were retrospectively considered not evaluable.

\section{Statistical Analysis}

Data were described as median and interquartile range (IQR) when continuous, and as absolute and relative frequency when categorical. The optimal cut-off of phenotypically abnormal event number for discriminating 'positive' FCM samples was found by constructing receiver operating characteristic $(\mathrm{ROC})$ curves, which were generated by calculating sensitivities and specificities of FCM data at several predetermined cut-off points on 2/3 of samples, randomly selected (testing population); the best cut-off was then confirmed on the remaining samples (validating population). ROC curve analysis showed that finding $\geq 5$ phenotypically abnormal events by FCM identified samples with higher risk of being positive at retrospective clinical outcome. Sensitivity, specificity, positive predictive value and negative predictive value were calculated for each method, together with their $95 \%$ confidence intervals $(95 \% \mathrm{Cl})$. Methods accuracy comparisons (intersample and inter-method) was assessed by means of a paired test (with Chi2 distribution) comparing the area under the ROC curves of sensitivity and specificity [15]. The Bonferroni correction was used for post-hoc comparisons of methods. Analyses were performed with the use of Stata 11 (StataCorp, College Station, TX, USA).

\section{Results}

Specimens and Clinical Settings 
In 6 cases with suspected hematologic malignancy, LP was performed in the presence of CNS symptoms with/without lymphoadenopathies; in the remaining cases, a hematologic malignancy was screened for disease localization. Sample distribution according to clinical setting is reported in Table 1. Fifty-five samples were drawn from newly diagnosed hematologic malignancy. In this setting, 14 samples (25\%) were evaluated in the presence of CNS signs and/or symptoms, while 41 samples (75\%) were evaluated in the context of prophylactic purposes according to the risk of CNS involvement/relapse [1618]. One-hundred sixty-six samples were drawn during follow-up. In this setting, 42 samples $(25.5 \%)$ were evaluated for suspected CNS relapse/progression in the presence of CNS signs/symptoms, while 124 samples (74.5\%) were drawn according to diseasespecific schedule [CNS signs/symptoms were present in $15(12 \%)$ and absent in 109 $(88 \%)$ cases].

Thirty-two samples from newly diagnosed hematologic malignancy (58\%) were evaluated only at diagnosis; in the remaining 23 cases (42\%), a median of 2 (IQR 1-3) follow-up samples per patient was also available. One-hundred twenty-three samples were instead available only during follow-up (median per patient 1, IQR 1-2, range 1-17).

CSF Assessment according to Clinical Follow-Up

During a a median follow-up of 11 months (IQR, 6-20 months) from sample withdrawal, 64/227 CSF samples (28\%) were assessed as positive and 163/227 CSF samples (72\%) were assessed as negative for hematologic malignancy localization by retrospective clinical outcome. The distribution of positive samples according to clinical setting is reported in Table 2. Eleven out of 55 CSF submitted in newly diagnosed hematologic malignancy were retrospectively assessed as positive for acute monoblastic leukemia $(n=1)$, diffuse large B-cell lymphoma (DLBCL) not otherwise specified (NOS) ( $n=5)$, 
follicular lymphoma $(n=1)$, and peripheral T-cell lymphoma NOS $(n=4)$. Fifty-three out of 166 CSF submitted during hematologic malignancy follow-up were assessed as positive for acute monoblastic leukemia ( $n=2)$, acute promyelocytic leukemia $(n=9), \quad B$ lymphoblastic leukemia/lymphoma (L/L) with recurrent genetic abnormalities $(n=4), B$ lymphoblastic L/L NOS $(n=10)$, B cell lymphoma, unclassifiable, with features intermediate between DLBCL and Burkitt lymphoma $(n=5)$, DLBCL NOS $(n=17)$, lymphoplasmacytic lymphoma $(n=1)$, nodal marginal zone lymphoma $(n=1)$, peripheral Tcell lymphoma NOS $(n=2)$, and T lymphoblastic $L / L(n=2)$.

Matching between FCM and $\mathrm{CM}$ according to retrospective clinical outcome

The matching between FCM and CM could be performed in 213 cases; in the remaining 14 , the results by each or both methods were retrospectively considered not evaluable for blood contamination. Matching of method assessments according to retrospective clinical outcome is reported in Table 3. Concordant results between FCM and CM were observed in 181 evaluable cases (85\%). One hundred fourty-five cases (68\%) were true negative by both methods, 26 cases (12.5\%) were true positive by both methods, 1 case $(0.5 \%)$ was false positive by both methods, and 9 cases (4\%) were false negative by both methods. The latter were samples from acute monoblastic leukemia $(n=1)$, acute promyelocytic leukemia $(n=1), \operatorname{DLBCL}$ NOS $(n=5)$, peripheral T-cell lymphoma NOS $(n=1)$, and $T$ lymphoblastic $L / L(n=1)$. Discordant results between FCM and CM were observed in 32 cases (15\%). FCM gave false negative results in 5 cases $(2.5 \%)$ with true positive CM. The latter were samples from acute promyelocytic leukemia $(n=2)$, DLBCL NOS ( $n=2)$, and B lymphoblastic L/L with recurrent genetic abnormalities $(n=1)$. FCM gave false positive results in 9 cases (4\%) with true negative CM. Clinical settings and immunophenotype of the latter are detailed in Table 4. Four out of 9 false positive results by FCM were related to either occult CNS disease at diagnosis $(\# 1,2,3)$ or minimal 
residual leptomeningeal disease under effective intrathecal treatment (\#8). FCM gave true negative results in 1 case $(0.5 \%)$ with false positive $\mathrm{CM}$, and true positive results in 17 cases $(8 \%)$ with false negative CM. Clinical settings and immunophenotype of the latter are detailed in Table 5.

Inter-Method Comparisons of Accuracy

Comparison with retrospective clinical outcome could be evaluated in 208 cases for CM, in 221 cases for FCM and in 224 cases for CMA. Sensitivity, specificity, positive predictive value, negative predictive value, and the results of inter-method comparisons of accuracy, both in all samples and in subsets of samples selected according to clinical interest, are reported in Table 6. The accuracy of CMA was significantly higher than that of $\mathrm{CM}$ in the analysis of all samples $(p<.0001)$, follow-up samples $(p<.0001)$, samples from patients with mature $B-/ T$-cell neoplasm $(p=.0021)$, and samples drawn after at least one intrathecal treatment $(p=.0001)$. In the analysis of these samples, CM accuracy was lower than that of FCM. Combining methods led to higher accuracy than either CM or FCM in the analysis of screening samples $(p=.2036)$, samples from patients with precursor lymphoid neoplasm $(p=.0656)$ and samples from patients with acute myeloid leukemia and related precursor neoplasm $(\mathrm{p}=.0574)$. FCM accuracy was lower than CM accuracy when acquiring $\leq 220$ (corresponding to the third tertile of distribution of) $\mathrm{CD} 45^{+}$cell events. In this setting, combining methods added to FCM a statistically significant advantage in accuracy $(p=.0043)$. On the contrary, when acquiring $>220 \mathrm{CD}^{4} 5^{+}$cell events FCM retained significantly higher accuracy than CM ( $p=.0065)$. In this setting, combining methods did not add to FCM any diagnostic advantage. Of note, both the positive and negative predictive values were high for all methods, overall and in each subgroup. Exceptions were acute myeloid leukemia and related precursor neoplasm, 
where the negative predictive values were low, and acquired $C D 45^{+}$Cells $\leq 220$, where the positive predictive values of FCM and CMA were low.

\section{Discussion}

Serial CSF studies represent an important criterion for the management of active CNS disease. However, few data are available on FCM/CM diagnostic performance in followup evaluations, since a definitive categorization has been reported difficult to obtain in the presence of hypocellular and/or little-sized samples $[6-8,10,11]$. In our study the majority of samples were drawn during follow-up. Neither cellularity, nor previous intrathecal therapy, nor sample size (CSF volumes ranged from 200 to $3400 \mu \mathrm{L}$ ) represented an exclusion criterion for the analysis. Instead, an independent clinical assessment provided by the planning of a retrospective longitudinal study was used, in order to test a diagnostic approach assuring the best sensitivity. To this end, (i) ROC curves of accuracy were used to establish the more appropriate number of FCM events for positive FCM, (ii) uncertain morphologic results were classified as positive $\mathrm{CM}$, and (iii) a combined method assessment (i.e., a positive assessment if at least one method gave positive results) was sampled.

The number of phenotypically abnormal events defining positive screening samples by FCM have been so far arbitrarily chosen, cut-offs of 10 to 30 events allowing FCM to retain higher sensitivity than $\mathrm{CM}$ in both prospective and retrospective studies [5-8]. By combining immunophenotype results with an all over independent clinical assessment, we identified the 5 cell event cut-off as the most accurate. In the screening setting, true positive FCM results, as well as false positive ones likely related to an occult CNS disease, displayed $\geq 20$ phenotypically abnormal events, according to previous observations $[6,19,20]$. However, in one case of newly diagnosed, clinically positive acute monoblastic leukemia, only six $\mathrm{CD}_{13^{+}} \mathrm{CD} 14^{-} \mathrm{CD} 34^{+} \mathrm{CD}^{+} 6^{+} \mathrm{CD} 45^{ \pm}$events were 
observed. This is likely to suggest that, in view of a disease with frankly abnormal phenotype, primary neoplastic contamination should be suspected even in the presence of very few pathological cells. Immunophenotype diagnostic performance was confirmed to be higher than morphologic one regardless the clinical setting analyzed, and found to reach $100 \%$ sensitivity when at least 220 leukocyte events could be analyzed [2,3,5$8,11,12]$. Moreover, follow-up FCM evaluations resulted as sensitive as screening ones, while follow-up morphologic evaluations did not. This is likely to indicate that intrathecal treatment-related cell changes do not affect immunophenotype diagnostic performance as much as morphologic one $[11,13]$.

Highest accuracy of an assessment combining immunophenotype and morphologic data has been so far displayed in previous studies $[2,3,5-8,10,11]$. According to our combined method assessment, $2.5 \%$ of total samples, resulting false negative by FCM, were rescued by true positive $\mathrm{CM}$, and $8 \%$ of total samples, resulting false negative by $\mathrm{CM}$, were rescued by true positive FCM. CMA sensitivity was higher than that of each method, predominantly (although not exclusively) due to FCM contribution. In particular, FCM allowed CMA to reach significantly higher sensitivity than $\mathrm{CM}$ in the setting of mature $\mathrm{B}$ /T-cell neoplasms, in which lymphocytes frequently display typical pathological phenotype patterns while looking reactive at morphology. Instead, in the setting of acute myeloid leukemia and related precursor neoplasms, where typical morphology of blast cells is much more identifiable, FCM and CM equally contributed to CMA sensitivity.

Evidence has been provided that CM evaluation of CSF is still essential in selected cases $[2,3,5-8,10,11]$. In our study, the setting in which CM retained a diagnostic advantage as compared to FCM was represented by very hypocellular samples, i.e. those samples in which FCM acquired less than 220 leukocyte events. In this case, CMA retained significantly higher sensitivity than FCM due to $\mathrm{CM}$ contribution. Only positive morphologic assessment reliably predicted CNS disease, as suggested by high positive predictive value. On the basis of previous data, in our study population the eight cases 
with uncertain $\mathrm{CM}$, each of them drawn in the follow-up setting, were considered positive for hematologic malignancy localization [1]. Comparison with retrospective clinical outcome demonstrated seven out of these eight to be true positive cases, so that such diagnostic approach increased CM sensitivity to the detritment of a mild impairment in specificity. Interestingly, in six out of these seven true positive cases immunophenotype could evaluate up to 300 leukocyte events. Therefore, although uncertain morphologic findings have been demonstrated to be definitively negative in the screening setting, they are likely to retain a more incisive diagnostic role in the evaluation of samples drawn in the aftermath [5].

In conclusion, FCM is confirmed to be the best diagnostic tool for detecting neoplastic cells in CSF from patients with hematologic malignancy, regardless the clinical setting. However, diagnostic advantage is obtained by combining FCM results with morphologic ones. The latter might be essential especially in evaluating clinically positive, nearly acellular follow-up samples.

\section{References}

[1] Schinstine M, Filie AC, Wilson W, Stetler-Stevenson M, Abati A (2006) Detection of malignant hematopoietic cells in cerebral spinal fluid previously diagnosed as atypical or suspicious. Cancer Cytopathol 108:157-162

[2] Finn WG, Peterson LC, James C, Goolsby CL (1998) Enhanced detection of malignant lymphoma in cerebrospinal fluid by multiparameter flow cytometry. Am J Clin Pathol 110:341-346

[3] French CA, Dorfman DM, Shaheen G, Cibas ES (2000) Diagnosing lymphoproliferative disorders involving the cerebrospinal fluid. Increased sensitivity using flow cytometric analysis. Diagnostic Cytopathol 23:369-374 
[4] Sayed D, Badrawy H, Ali AMA, Shaker S (2009) Immunophenotyping and immunoglobulin heavy chain gene rearrangement analysis in cerebrospinal fluid of pediatric patients with acute lymphoblastic leukaemia. Leuk Res 33: 655-661

[5] Bromberg JEC, Breems DA, Kraan PhDJ, Bikker G, van der Holt B, Sillevis Smith P, van den Bent MJ, van't Veer M, Gratama JW (2007) CSF flow cytometry greatly improves diagnostic accuracy in CNS hematologic malignancies. Neurology 68:1674-1679

[6] Hegde U, Filie A, Little RF, Janik JE, Grant N, Steinberg SM, Dunleavy K, Jaffe ES, Abati A, Stetler-Stevenson M, Wilson WH (2004) High incidence of occult leptomenigeal disease detected by flow cytometry in newly diagnosed aggressive B-cell lyphomas at risk for central nervous system involvement. The role of cytometry versus cytology. Blood 105:496-502

[7] Di Noto R, Scalia G, Abate G, Gorrese M, Pascariello C, Raia M, Morabito P, Capone F, Lo Pardo C, Mirabelli P, Mariotti E, Del Vecchio L (2008) Critical role of multidimensional flow cytometry in detecting occult leptomeningeal disease in newly diagnosed aggressive B-cell lymphomas. Leuk Res 32: 1196-1199

[8] Quijano S, Lopez A, Sancho JM, Panizo C, Deben G, Castilla C, Garcia-Vela JA, Salar A, Alonso-Vence N, Gonzalez-Barca E, Penalver FJ, Plaza-Villa J, Morado M, Gargia-Marco J, Arias J, Briones J, Ferrer S, Capote J, Nicolas C, Orfao A (2009) Identification of leptomeningeal disease in aggressive B-cell non-Hodgkin's lymphoma: improved sensitivity of flow cytometry. J Clin Oncol 27:1462-1469

[9] Subirà D, Castanon S, Roman A, Aceituno E, Jimenez-Garofano C, Jimenez A, Garcia R, Bernacer M (2001) Flow cytometry and the study of central nervous disease in patients with acute leukaemia. $\mathrm{Br} \mathrm{J}$ Heamtol 112: 381-384

[10] Roma AA, Garcia A, Avagnina A, Rescia C, Elser B (2002) Lymphoid and myeloid neoplasm involving cerebrospinal fluid: comparison of morphologic examination and immunophenotyping by flow cytometry. Diagnostic Cytopathol 27:271-275 
[11] Urbanits S, Griesmacher A, Hopfinger G, Stockhammer G, Karimi A, Muller MM, Pittermann E, Grisold W (2002) FACS analysis - A new and accurate tool in the diagnosis of lymphoma in the cerebrospinal fluid. Clinica Chimica Acta 317:101107

[12] Wu JM, Gerrgy MF, Burroughs FH, Weir EG, Rosenthal DL, Ali SZ (2009) Lymphoma, leukemia, and pleiocytosis in cerebrospinal fluid. Is accurate cytopathologic diagnosis possible based on morphology alone? Diagnostic Cytopathol 37:820-823

[13] Peter A (1974) Cytological changes in the cerebrospinal fluid following intrathecal methotrexate treatment. Confin Neurol 36:186-196

[14] Cesana C, Klersy C, Scarpati B, Brando B, Volpato E, Bertani G, Faleri M, Nosari A, Cantoni S, Ferri U, Scampini L, Barba C, Lando G, Morra E, Cairoli R (2010) Flow cytometry vs cytomorphology for the detection of hematologic malignancy in body cavity fluids. Leuk Res 34:1027-1034.

[15] DeLong ER, DeLong DM, Clarke-Pearson DL (1988) Comparing the areas under two or more correlated receiver operating characteristic curves: a nonparametric approach. Biometrics 44:837-845

[16] Tomita N, Kodama F, Kanamori H, Motomura S, Ishigatsubo Y (2002) Prophylactic intrathecal methotrexate and hydrocortisone reduces central nervous system recurrence and improves survival in aggressive non-Hodgkin lymphoma. Cancer 95:576-580

[17] McMillan A (2005) Central nervous system-directed preventative therapy in adults with lymphoma. $\mathrm{Br} \mathrm{J}$ Haematol 131:13-21

[18] Hill QA, Owen RG (2006) CNS prophylaxis in lymphoma: who to target and what therapy to use. Blood Reviews 20:319-332 
[19] Nowakowski GS, Call TG, Morice WG, Kurtin PJ, Cook RJ, Zent CS (2005) Clinical significance of monoclonal B cells in cerebrospinal fluid. Clinical Cytometry 63B:2327

[20] Schmidt-Hieber M, Thiel E, Keilholz U (2005) Spinal paraparesis due to leukemic meningitis in early-stage chronic lymphocytic leukaemia. Leuk Lymph 46:619-621 


\section{Suspected Hematological Malignancy}

Disclosed Hematological Malignancy (WHO)

At Diagnosis

Precursor Lymphoid Neoplasms

B Lymphoblastic Leukemia/Lymphoma, NOS

B Lymphoblastic Leukemia/Lymphoma with Recurrent Genetic Abnormalities

T Lymphoblastic Leukemia/Lymphoma

Mature B-/T-Cell Lymphoid Neoplasms

Chronic Lymphocytic Leukemia/Small Lymphocytic Lymphoma

B-Cell Lymphoma, Unclassifiable, with Features Intermediate between DLBCL and BL

$\mathrm{BL}$

DLBCL NOS

Follicular Lymphoma

Mantle Cell Lymphoma

Peripheral T-Cell Lymphoma NOS

Plasma Cell Myeloma

T Cell/Hystiocyte-Rich Large B Cell Lymphoma

Mature B-Cell Lymphoid Neoplasm, Unclassifiable

Acute Myeloid Leukemias and Related Precursor Neoplasms

Acute Monoblastic Leukemia

Blastic Plasmacytoid Dendritic Cell Neoplasm

Myelodysplastic syndromes

Refractory Anemia with Excess Blasts

\section{During Follow-Up}

Precursor Lymphoid Neoplasms

B Lymphoblastic Leukemia/Lymphoma NOS

B Lymphoblastic Leukemia/Lymphoma with Recurrent Genetic Abnormalities

T Lymphoblastic Leukemia/Lymphoma

Mature B-/T-Cell Lymphoid Neoplasms

B-Cell Lymphoma, Unclassifiable, with Features Intermediate between DLBCL and BL

$\mathrm{BL}$

DLBCL NOS

Follicular Lymphoma

Lymphoplasmacytic Lymphoma

Nodal Marginal Zone Lymphoma

Peripheral T-Cell Lymphoma NOS

Plasma Cell Myeloma

Primary DLBCL of the CNS

Mature B-Cell Lymphoid Neoplasm, Unclassifiable

Acute Myeloid Leukemias and Related Precursor Neoplasms 18

Acute Monoblastic Leukemia

Acute Myeloid Leukemia with Recurrent Genetic Abnormalities

Acute Myelomonocytic Leukemia

Acute Promyelocitic Leukemia

Blastic Plasmacytoid Dendritic Cell Neoplasm 
Table 2. Cerebrospinal Fluids Positive for Hematological Malignancy according to Retrospective Clinical Outcome

Number of Samples (\%)

Suspected Hematological Malignancy $(n=6)$

0

Disclosed Hematological Malignancy $(n=221)$

$64(29)$

At Diagnosis ( $n=55)$

$11(20)$

During Follow-Up ( $n=166)$

53 (32)

According to Treatment Schedule $(n=124)$

$25(20)$

Relapse Suspected ( $n=19)$

14 (74)

Progression Suspected ( $n=23)$

$14(61)$ 
and CM Results on 227 CSF Samples, Compared with Retrospective Clinical Outcome

\begin{tabular}{|c|c|c|c|c|c|c|c|}
\hline \multicolumn{2}{|c|}{$\begin{array}{c}\text { Concordant } \\
\mathrm{CM} \text { and FCM }(\mathrm{n}=181)\end{array}$} & \multicolumn{2}{|c|}{$\begin{array}{c}\text { Discordant } \\
\mathrm{CM} \text { and FCM }(\mathrm{n}=32)\end{array}$} & & \multicolumn{3}{|c|}{$\begin{array}{c}\text { Partial } \\
\mathrm{CM} \text { and/or FCM }(\mathrm{n}=14)\end{array}$} \\
\hline $\begin{array}{l}\text { FCM - } \\
\text { CM - }\end{array}$ & $\begin{array}{c}\mathrm{FCM}+ \\
\mathrm{CM}+\end{array}$ & $\begin{array}{l}\text { FCM - } \\
\text { CM + }\end{array}$ & $\begin{array}{c}\mathrm{FCM}+ \\
\mathrm{CM}-\end{array}$ & $\begin{array}{l}\text { FCM - } \\
\text { CM ne }\end{array}$ & $\begin{array}{l}\mathrm{FCM}+ \\
\mathrm{CM} \text { ne }\end{array}$ & $\begin{array}{l}\text { CM - } \\
\text { FCM ne }\end{array}$ & $\begin{array}{c}\mathrm{CM}+ \\
\mathrm{FCM} \text { ne }\end{array}$ \\
\hline 145 & 1 & 1 & 9 & 6 & 0 & 1 & 0 \\
\hline 9 & 26 & 5 & 17 & 1 & 1 & 0 & 2 \\
\hline
\end{tabular}

logy; CSF: Cerebrospinal Fluid; FCM: Flow Cytometry; ne: Not Evaluable 
Table 4. Immunophenotype Findings in 9 Cases of False Positive Fow Cytometry (and True Negative Cytomorphology) according Retrospective Clinical Outcome

\begin{tabular}{|c|c|c|c|c|}
\hline \# & Clinical Setting & Immunophenotype & $\begin{array}{c}\mathbf{N}^{\circ} \text { of }+ \text { Events } \\
\left(\% \text { of CD45 }{ }^{+} \text {Cells) }\right.\end{array}$ & \\
\hline 1 & CLL/SLL, Screening & $\mathrm{CD}^{+} \mathrm{CD} 19^{+} \mathrm{CD}^{2} 3^{+}$Cells & $82(17.4)$ & Negative MRI; CNS sympt \\
\hline 2 & CLL/SLL, Screening & $\mathrm{CD}^{+} \mathrm{CD} 19^{+} \mathrm{CD}_{23}{ }^{+}$Cells & $24(10.9)$ & Negative MRI; CNS sympt \\
\hline 3 & DLBCL NOS, Screening & $\mathrm{CD}_{10}{ }^{+} \mathrm{CD} 19^{+} \mathrm{CD} 2 \mathrm{O}^{+} \mathrm{SSC}^{++}$Cells & $20(10.5)$ & No CNS Signs/Symptoms \\
\hline 4 & $\begin{array}{l}\text { T Lymphoblastic L/L, } \\
\text { Screening }\end{array}$ & $\mathrm{CD}^{-} \mathrm{CD}^{-} \mathrm{CD}^{-} \mathrm{CD} 7^{ \pm} \mathrm{CD} 34^{ \pm} \mathrm{CD} 45^{ \pm}$Cells & $10(20)$ & No CNS Signs/Symptoms \\
\hline 5 & DLBCL NOS, Relapse & $\mathrm{CD}_{19}{ }^{+} \mathrm{CD} 20^{+} \mathrm{CD} 79 \mathrm{a}^{+}$Cells & $8(5)$ & No CNS Signs/Symptoms \\
\hline 6 & $\begin{array}{l}\text { B Lymphoblastic L/L with } \\
\text { Recurrent Genetic } \\
\text { Abnormalities, Follow-up } \\
\text { According to Schedule }\end{array}$ & $\mathrm{CD}_{10}{ }^{+} \mathrm{CD} 20^{+} \mathrm{CD} 34^{+} \mathrm{CD} 45^{-}$Cells & $7(2.1)$ & No CNS Signs/Symptoms \\
\hline 7 & $\begin{array}{l}\text { B Lymphoblastic L/L NOS, } \\
\text { Follow-up According to } \\
\text { Schedule }\end{array}$ & $\mathrm{CD}_{10}{ }^{+} \mathrm{CD} 20^{+} \mathrm{CD} 34^{+} \mathrm{CD} 45^{ \pm}$Cells & $7(5.5)$ & No CNS Signs/Symptoms \\
\hline 8 & $\begin{array}{l}\text { DLBCL NOS, Follow-up } \\
\text { According to Schedule }\end{array}$ & $\mathrm{CD}_{10}{ }^{+} \mathrm{CD} 19^{+} \mathrm{CD} 2 \mathrm{O}^{+} \mathrm{SSC}^{++}$Cells & $9.5(12.8)$ & No CNS Signs/Symptoms \\
\hline 9 & $\begin{array}{l}\text { PTC Lymphoma NOS, } \\
\text { Follow-up According to } \\
\text { Schedule }\end{array}$ & $\mathrm{CD}^{+} \mathrm{CD}^{+} \mathrm{CD} 4^{+} \mathrm{CD} 5^{+} \mathrm{CD} 7^{+} \mathrm{CD} 8^{+}$Cells & $7(5)$ & Polyclonal TCR by Molecu \\
\hline
\end{tabular}

CLL/SLL: Chronic Lymphocytic Leukemia/Small Lymphocytic Lymphoma; CNS: Central Nervous System; DLBCL: Diffuse Large B-Cell Lymphoma L/L: Leukemia/Lymphoma; MRI: Magnetic Resonance Imaging; NHL: Non-Hodgkin Lymphoma; NOS: Not Otherwise Specified; PTC: Peripheral T Cell; SSC: Side Scatter; TCR: T-Cell Receptor 
Clinical Setting

ute Monoblastic Leukemia taging)

ute Monoblastic Leukemia ollow-up)

Cell Lymphoblastic L/L

S (Follow-up)

Cell Lymphoblastic L/L,

S (Follow-up)

Cell Lymphoblastic L/L,

SS (Follow-up)

Cell Lymphoblastic L/L,

S (Follow-up)

Cell Lymphoma,

classifiable, with Features

ermediate between

$\mathrm{BCL}$ and BL (Follow-up)

Cell Lymphoma,

classifiable, with Features

ermediate between

$\mathrm{BCL}$ and BL (Follow-up)

Cell Lymphoma,

classifiable, with Features

ermediate between

$\mathrm{BCL}$ and $\mathrm{BL}$ (Follow-up)

BCL, NOS (Staging)

BCL, NOS (Follow-up)

BCL, NOS (Follow-up)

BCL, NOS (Follow-up)

BCL, NOS (Follow-up)

Ilicular Lymphoma

taging)

ripheral T Cell

mphoma, NOS (Staging)

ripheral T Cell

mphoma, NOS (Follow-
Immunophenotype

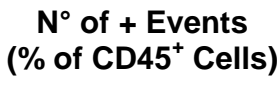

$\mathrm{CD}^{+} 3^{+} \mathrm{CD} 14^{-\mathrm{CD}} 34^{+} \mathrm{CD}^{-} 6^{+} \mathrm{CD} 45^{ \pm}$

Blasts

$\mathrm{CD} 10^{+} \mathrm{CD} 19^{+} \mathrm{CD} 20^{+} \mathrm{CD} 45^{ \pm}$Blasts

$\mathrm{CD}_{10}{ }^{+} \mathrm{CD} 19^{+} \mathrm{CD} 20^{+} \mathrm{CD} 45^{ \pm}$Blasts

$\mathrm{CD}^{+} 0^{+} \mathrm{CD} 19^{+} \mathrm{CD} 20^{+} \mathrm{CD} 34^{-} \mathrm{CD} 45^{ \pm}$

Blasts

$\mathrm{CD}^{+} 0^{+} \mathrm{CD} 19^{+} \mathrm{CD} 20^{+} \mathrm{CD} 34^{-} \mathrm{CD} 45^{ \pm}$

Blasts

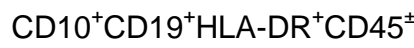

Lymphocytes

$\mathrm{CD}^{+} 0^{+} \mathrm{CD} 19^{+} \mathrm{HLA}-\mathrm{DR}^{+} \mathrm{CD} 45^{ \pm}$

Lymphocytes

$\mathrm{CD}_{10}{ }^{+} \mathrm{CD} 19^{+} \mathrm{HLA}-\mathrm{DR}^{+} \mathrm{CD} 45^{ \pm}$

Lymphocytes

CD10 ${ }^{+}$CD19 $9^{+}$Lymphocytes

CD10 ${ }^{+}$CD19 ${ }^{+}$CD34- Lymphocytes

$\mathrm{CD} 0^{+} \mathrm{CD}_{19}{ }^{+} \mathrm{HLA}^{-\mathrm{DR}^{+}}$Lymphocytes

$\mathrm{CD}^{+} 0^{+} \mathrm{CD}_{19}{ }^{+} \mathrm{HLA}^{-\mathrm{DR}^{+}}$Lymphocytes

$\mathrm{CD}^{+} 0^{+} \mathrm{CD}_{19}{ }^{+} \mathrm{HLA}^{-\mathrm{DR}^{+}}$Lymphocytes

CD $10^{+} \mathrm{CD} 19^{+} \mathrm{CD}_{20}{ }^{+} \mathrm{k}^{+}$Lymphocytes

$\mathrm{CD}^{+} \mathrm{CD}^{+} \mathrm{CD}^{-} \mathrm{CD}^{+} \mathrm{CD}^{+} \mathrm{CD}^{+}$

Lymphocytes

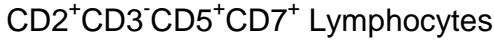

\section{$6(5)$}

$12(4)$

$76(10)$

$667(57)$

$13(2)$

$144(89.4)$

$100(62)$

45 (17.2)

$70(8.5)$

$315(73.5)$

$6(1.6)$

$180(28)$

$19(15)$

Definitive Retrospective Clinical Assessment

CNS localization; Positive MRI CNS Symptoms

Residual Meningeal Disease; Positive MRI; CNS Symptoms

Residual Meningeal Disease; Positive MRI; CNS Symptoms

Residual Meningeal Disease; Positive MRI; CNS Symptoms

Residual Meningeal Disease; Positive MRI; CNS Symptoms

Residual Meningeal Disease; Positive MRI

CNS Relapse; Positive MRI

Residual Meningeal Disease; CNS Symptoms

CNS Progression; Positive MRI; CNS Symptoms

CNS localization; Positive MRI

Residual Meningeal Disease; Positive MRI; CNS Symptoms

Residual Meningeal Disease; Positive MRI; CNS Symptoms

Residual Meningeal Disease; Positive MRI; CNS Symptoms

Residual Meningeal Disease; Positive MRI; CNS Symptoms

Progressive Disease; Deceased

CNS Localization; CNS Symptoms

$297(100)$
CNS Localization; Monoclonal TCR by Molecular Biology

Burkitt Lymphoma; CNS: Central Nervous System; CSF: Cerebrospinal Fluid; DLBCL: Diffuse Large B Cell Lymphoma; L/L: Leukemia/Lymphom : Magnetic Resonance Imaging; NOS: Not Otherwise Specified; TCR: T-Cell Receptor. 
Table 6. Inter-Method Comparisons of Accuracy in the Analysis of Cerebrospinal Fluids and their Subsets

\begin{tabular}{|c|c|c|c|c|}
\hline & $\mathrm{N}^{\circ}$ & $\%$ Sensitivity $(95 \% \mathrm{Cl})$ & $\%$ Specificity $(95 \% \mathrm{Cl})$ & $\%$ PPV \\
\hline \multicolumn{5}{|l|}{ All } \\
\hline Cytomorphology ${ }^{2}$ & 208 & $65.8(48.6-80.4)$ & $93.8(88.9-97)$ & 71.4 \\
\hline Flow Cytometry & 221 & $74.6(61.6-85)$ & $93.8(88.9-97)$ & 81.5 \\
\hline Combined Method $^{0}$ & 224 & $83.6(71.9-91.8)$ & $93.3(88.2-96.6)$ & 82.3 \\
\hline \multicolumn{5}{|c|}{ New diagnosis, Relapse, Progression } \\
\hline Cytomorphology & 85 & $67.4(49-81.4)$ & $98(89.6-100)$ & 96( \\
\hline Flow Cytometry & 90 & $75.7(58.8-88.2)$ & $88.7(77-95.7)$ & 82.4 \\
\hline Combined Method & 92 & $81.6(65.7-92.3)$ & $88.9(77.4-95.8)$ & 83.8 \\
\hline \multicolumn{5}{|c|}{ Follow-Up according to schedule } \\
\hline Cytomorphology & 117 & $39.1(19.7-61.5)$ & $99(94.6 .100)$ & 90 \\
\hline Flow Cytometry & 125 & 72.7 (49.8-89.3) & $96.1(90.4-98.9)$ & 80( \\
\hline Combined Method ${ }^{0}$ & 126 & $87(66.4-97.2)$ & $95.1(89-98.4)$ & $80(5$ \\
\hline \multicolumn{5}{|c|}{ Mature B-/T-Cell Neoplasm } \\
\hline Cytomorphology ${ }^{2}$ & 120 & $52.8(35.5-69.6)$ & $98.9(93.9-100)$ & 95 \\
\hline Flow Cytometry & 127 & $77.1(59.9-89.6)$ & $92.4(84.9-96.9)$ & 79.4 \\
\hline Combined Method $^{0}$ & 128 & $83.3(67.2-93.6)$ & $92.4(84.9-96.9)$ & 81.1 \\
\hline \multicolumn{5}{|c|}{ Precursor Lymphoid Neoplasm } \\
\hline Cytomorphology & 61 & $54.5(23.4-83.3)$ & $98.1(89.9-100)$ & 85.7 \\
\hline Flow Cytometry & 66 & $76.9(46.2-95)$ & $94.3(84.3-98.8)$ & 76. \\
\hline Combined Method & 67 & $84.6(54.6-98.1)$ & $92.6(82.1-97.9)$ & 73.3 \\
\hline \multicolumn{5}{|c|}{ Previous Intrathecal Therapy } \\
\hline Cytomorphology ${ }^{2}$ & 131 & $57.5(40.9-73)$ & 99 (99.4-100) & 95.8 \\
\hline Flow Cytometry & 139 & $72.5(56.1-85.4)$ & $94.9(88.6-98.3)$ & $85.3(6$ \\
\hline Combined Method $^{0}$ & 141 & $85.7(71.5-94.6)$ & $93.9(87.3-97.7)$ & 85.7 \\
\hline \multicolumn{5}{|c|}{ AML and Related Precursor Neoplasm } \\
\hline Cytomorphology & 18 & $66.7(34.9-90.1)$ & $100(54.1-100)$ & 100 \\
\hline Flow Cytometry & 19 & $63.6(30.8-89.1)$ & $100(63.1-100)$ & 10 \\
\hline Combined Method & 20 & $83.3(51.6-97.9)$ & $100(63.1-100)$ & 100 \\
\hline \multicolumn{5}{|c|}{ Acquired CD $45^{+}$Cells $\leq 220$} \\
\hline Cytomorphology & 138 & $43.5(23.2-65.6)$ & $99.2(95.4-100)$ & 90.9 \\
\hline Flow Cytometry ${ }^{2}$ & 145 & $31.8(13.9-54.9)$ & $95.1(89.7-98.2)$ & 53.8 \\
\hline Combined Method ${ }^{1}$ & 148 & $58.3(36.6-77.9)$ & $94.4(88.7-97.7)$ & 66.7 \\
\hline \multicolumn{5}{|c|}{ Acquired $C D 45^{+}$Cells $>220$} \\
\hline Cytomorphology ${ }^{1,2}$ & 67 & $65.7(47.8-80.9)$ & $97.1(85.1-99.9)$ & 95.8 \\
\hline Flow Cytometry & 73 & $100(90.3-100)$ & $89.2(74.6-97)$ & 90( \\
\hline Combined Method $^{0}$ & 73 & $100(90.3-100)$ & $89.2(74.6-97)$ & 90( \\
\hline
\end{tabular}

AML: Acute Myeloid Leukemia; Cl: Confidence Interval; NPV: Negative Predictive value; PPV: Positive Predictive Value.

* Test (with Chi2 Distribution) Comparing the Receiver Operating Characteristic curves of Sensitivity and Specificity.

$0,1,2$ Post-hoc Comparisons: Significant Differences after Bonferroni Correction $(p<.017):{ }^{0}$ vs Cytomorphology; ${ }^{1}$ vs Flow Cytometry; ${ }^{2}$ vs Combined method 